\title{
Lihassolun kokoon kannattaa kiinnittää huomiota
}

Marita Ruusunen ja Eero Puolanne

HY/elintarviketeknologian laitos, Viikki EE, PL 66, 00014 Helsingin yliopisto, marita.ruusunen@helsinki.fi, eero.puolanne@helsinki.fi

\section{Tiivistelmä}

Sikojen ja lihasten kasvaessa lihassolujen poikkipinta-ala ja pituus kasvavat. Rasvaisissa ruhoissa lihassolut ovat kuitenkin pienempiä kuin samanpainoisissa vähärasvaisissa ruhoissa. Tässä tutkimuksessa oli tarkoitus selvittää, millainen vaihtelu on lihassolujen poikkipinta-alassa samankokoisissa ulkofileissä (longissimus dorsi -lihas). Tutkimuksessa oli 27 maatiaista ja 28 yorkshirea, joiden elopainot vaihtelivat 95 kilosta 100 kiloon. Lihasnäytteet lihassolujen koon mittaamiseksi otettiin 35 minuuttia teurastuksen jälkeen, jäädytettiin nestemäisessä typessä ja säilytettiin -80 asteessa määritykseen asti. Lihassolujen poikkipinta-alat mitattiin longissimus dorsi-lihaksesta kuvankäsittelylaitteella leikkeistä, jotka oli värjätty myosiini-ATPaasi-menetelmällä. Ulkofileen poikkipinta-ala mitattiin vuorokausi teurastuksen jälkeen leikkuun yhteydessä.

Ulkofileen poikkipinta-ala oli kolmessa siassa välillä $30-35 \mathrm{~cm}^{2}, 18$ siassa välillä $35,1-40 \mathrm{~cm}^{2}$, 22 siassa välillä $40,1-45 \mathrm{~cm}^{2}$ ja 12 siassa välillä $45,1-50 \mathrm{~cm}^{2}$. Lihassolun keskimääräinen poikkipinta-ala vaihteli jokaisessa edellä mainitussa ryhmässä huomattavasti. Imisissä oli sekä lihassolujen poikkipinta-ala että fileen poikkipinta-ala suurempi kuin leikossa $(\mathrm{P}<0,01)$. Rotujen välillä ei eroa todettu $(\mathrm{P}>0,05)$. Johtopäätöksenä voidaan todeta, että samassa elopainossa ja samankokoisessa sian ulkofileessä lihassolun keskimääräinen poikkipinta-ala voi vaihdella huomattavasti. Tätä ominaisuutta kannattaisi hyödyntää valittaessa sikoja jatkojalostukseen. Vaikka toistaiseksi ei ole selkeästi osoitettu lihassolun koon yhteyttä lihan laatuun, voidaan kuitenkin oletettaa, että suurempi määrä pieniä lihassoluja antaa lihakselle suuremman kasvupotentiaalin ilman että lihan ja ruhon laatu heikkenevät.

Asiasanat maatiainen, yorkshire, ulkofilee, lihassolun koko 


\section{Johdanto}

Lihas koostuu lihassoluista. Sian lihassolujen lukumäärä on määräytynyt pääosin jo ennen syntymää. Sian kasvaessa sekä lihassolujen poikkipinta-ala että pituus kasvavat (Chrystall ym.,1969). Ruhon rasvaisuus vaikuttaa lihassolujen poikkipinta-alaan siten, että rasvaisissa ruhoissa lihassolut ovat pienempiä kuin samanpainoisissa vähärasvaisissa ruhoissa (Seideman ym., 1989).

Lihassoluja on kolmea eri tyyppiä: punaisia, valkoisia ja välimuotoa olevia. Sian ulkofilee (longissimus dorsi -lihas) sisältää noin 80 prosenttia valkoisia lihassoluja laskettuna lukumäärän perusteella ja yli 90 prosenttia laskettuna pinta-alaosuuksien perusteella. Tämän vuoksi valkoisten lihassolujen poikkipinta-ala määrää lihassolun keskimääräisen poikkipinta-alan tässä lihaksessa (Ruusunen ym., 1996).

Lihassolutyyppi ja lihassolun koko vaikuttavat lihassolun toimintaan elävässä eläimessä sekä myös siihen mitä lihassolussa tapahtuu lihaksen muuttuessa lihaksi teurastuksen jälkeen. Oksidatiiviset punaiset ja välimuotoa olevat lihassolut ovat poikkipinta-alaltaan pieniä ja niiden ympärillä on paljon hiusverisuonia eli kapillaareja. Ne sisältävät paljon myoglobiinia sekä mitokondrioita, jolloin pääasiassa punaisia ja välimuotoa olevia lihassoluja sisältävät tummat lihakset pystyvät hyödyntämään paremmin happea kuin valkoisia lihassoluja sisältävät vaaleat lihakset. Valkoiset lihassolut ovat poikkipinta-alaltaan suuria ja niiden ympärillä on vähän kapillaareja. Aineenvaihdunnaltaan valkoiset lihassolut ovat glykolyyttisiä sisältäen paljon glykogeenia ja muodostaen helposti laktaattia.

Sian elopaino ja ruhon rasvaisuus vaikuttavat sekä lihassolun kokoon että ulkofileen kokoon. Tämän vuoksi on tärkeää ottaa huomioon sekä sian elopaino että ruhon lihaisuus/rasvaisuus, kun verrataan lihassolujen kokoja eri sioissa. Tässä tutkimuksessa oli tarkoitus selvittää, millainen vaihtelu on lihassolujen poikkipinta-alassa samankokoisissa ulkofileissä (longissimus dorsi -lihas) sioissa, joiden elopaino vaihteli 95 kilosta 100 kiloon.

\section{Aineisto ja menetelmät}

Tutkimuksessa oli 27 maatiaista ja 28 yorkshirea. Joukossa oli sekä imisiä että leikkoja. Sikojen elopaino vaihteli vaihteli välillä $95-100 \mathrm{~kg}$. Lihasnäytteet lihassolujen koon mittaamiseksi otettiin 35 minuuttia teurastuksen jälkeen, jäädytettiin nestemäisessä typessä ja säilytettiin -80 asteessa määritykseen asti. Lihassolujen poikkipinta-alat mitattiin longissimus dorsi -lihaksesta kuvankäsittelylaitteella leikkeistä, jotka oli värjätty myosiini-ATPaasi-menetelmällä (Brooke ja Kaiser, 1970). Ulkofileen poikkipinta-ala mitattiin vuorokausi teurastuksen jälkeen leikkuun yhteydessä. Erot rotujen ja sukupuolten välillä testattiin varianssianalyysillä (SAS 1999).

\section{Tulokset ja tulosten tarkastelu}

Ulkofileen poikkipinta-ala oli kolmessa siassa välillä $30-35 \mathrm{~cm}^{2}, 18$ siassa välillä $35,1-40 \mathrm{~cm}^{2}, 22$ siassa välillä $40,1-45 \mathrm{~cm}^{2}$ ja 12 siassa välillä $45,1-50 \mathrm{~cm}^{2}$. Imisillä oli poikkipinta-alaltaan suurempi ulkofilee $(\mathrm{P}<0,05)$ ja poikkipinta-alaltaan keskimäärin suuremmat lihassolut $(\mathrm{P}<0,05)$ kuin leikoilla. Rotujen välillä ei eroja todettu (P>0,05) (Taulukko 1). Myös Karlsson ym. (1994) ja Ruusunen ym. (1996) ovat osoittaneet, että imisissä on suurempi ulkofileen poikkipinta-ala sekä keskimäärin suuremmat lihassolut kuin leikoissa.

Kuvissa 1 ja 2 on esitetty lihassolujen poikkipinta-ala erikokoisissa sian ulkofileissä, kun elopaino vaihtelee 95 ja $100 \mathrm{~kg}: n$ välillä. Samankokoisessa sian ulkofileessä lihassolun koko vaihtelee huomattavasti kummassakin rodussa ja kummassakin sukupuolessa, eli samankokoinen ulkofilee voi koostua joko pienemmästä määrästä suuria lihassoluja tai suuremmasta määrästä pieniä lihassoluja.

Syntymän jälkeen lihassolut ovat oksidatiivisia johtuen pienistä lihassoluista sekä suuresta kapillaaritiheydestä lihaksessa, mutta kun lihassolut kasvavat, ne muuttuvat anaerobisemmiksi. Jos lihassolut ovat pieniä ja niitä on paljon, lihas voi kasvaa enemmän ilman, että oksidatiivisuus vähenee verrattuna siihen, että lihas koostuisi pienemmästä määrästä suuria lihassoluja (Ashmore ja Vigneron 1988). Jos valintaperusteena käytettäisiin pienempää lihassolujen kokoa, voisi olettaa, että sikojen lihakset olisivat oksidatiivisempia ja kestäisivät paremmin teurastuksen aiheuttaman stressin, jolloin $\mathrm{pH}$ laskisi teurastuksen jälkeen hitaammin ja myös lihan laatu olisi parempi.

Toistaiseksi ei ole kuitenkaan selkeästi osoitettu lihassolun koon yhteyttä lihan laatuun; ei tiedetä, mikä pitäisi lihassolun koon olla, jotta siat kasvaisivat nopeasti ja ruhon punaisen lihan osuus olisi mahdollisimman suuri, valkoiset lihakset olisivat mahdollisimman oksidatiivisia sekä myös lihan ais- 
tinvarainen ja teknologinen laatu olisi hyvä. Voidaan kuitenkin oletettaa, että suurempi määrä pieniä lihassoluja antaa lihakselle suuremman kasvupotentiaalin ilman että lihan ja ruhon laatu heikkenevät.

\section{Johtopäätökset}

Johtopäätöksenä tästä tutkimuksesta voidaan todeta, että samassa elopainossa ja samankokoisessa sian ulkofileessä lihassolun keskimääräinen poikkipinta-ala vaihtelee huomattavasti. Tätä ominaisuutta voisi hyödyntää valittaessa sikoja jatkojalostukseen. Vaikka toistaiseksi ei ole selkeästi osoitettu lihassolun koon yhteyttä lihan laatuun, voidaan kuitenkin oletettaa, että suurempi määrä pieniä lihassoluja antaa lihakselle suuremman kasvupotentiaalin ilman että lihan ja ruhon laatu heikkenevät.

\section{Kirjallisuus}

Ashmore, C.R. \& Vigneron, P. 1988. Biological bases of carcass and meat quality and their relationship with growth. Proc. $3^{\text {rd }}$ World Congress on sheep and beef cattle breeding. Paris. Vol. 1. pp. 369-380. INRA, Publ., Paris. p. 714.

Brooke, M. H. \& Kaiser, K. K. 1970. Muscle fiber types: How many and what kind. Arch. Neurol. 123: 369379.

Chrystall, B.B., Zobrisky, S.E. \& Bailey, M.E. 1969. Longissimus muscle growth in swine. Growth 33: 361370.

Karlsson, A., Essen-Gustavsson, B. \& Lundström, K. 1994. Muscle glycogen depletion pattern in halothanegene-free pigs at slaughter and its relation to meat quality. Meat Sci. 38: 91-101.

Ruusunen, M., Sevon-Aimonen, M.-L. \& Puolanne, E. 1996. Composition and cross-sectional area of muscle fibre types in relation to daily gain and lean and fat content of carcass in Landrace and Yorkshire pigs. Agricultural and Food Science in Finland 5, 593-600.

SAS. 1999. SAS/STAT User's Guide, Version 8, Cary, NC:SAS Institute Inc.

Seideman, S.C., Crouse, J.D. \& Mersmann, H.J. 1989. Carcass, muscle and meat characteristics of lean and obese pigs. J. Anim. Sci. 67: 2950-2955.

Taulukko 1. Elopaino $(\mathrm{kg})$, fileen poikkipinta-ala $\left(\mathrm{cm}^{2}\right)$ ja keskimääräinen lihassolun poikkipinta-ala $\left(\mu \mathrm{m}^{2}\right)$ longissimus dorsi -lihaksessa.

\begin{tabular}{lcccccc}
\hline & $\begin{array}{l}\text { Leikot } \\
(\mathrm{N}=28)\end{array}$ & $\begin{array}{l}\text { Imisät } \\
(\mathrm{N}=27)\end{array}$ & $\mathrm{P}$ & $\begin{array}{l}\text { Maatiainen } \\
(\mathrm{N}=27)\end{array}$ & $\begin{array}{l}\text { Yorkshire } \\
(\mathrm{N}=28)\end{array}$ & $\mathrm{P}$ \\
\hline $\begin{array}{l}\text { Elopaino } \\
(\mathrm{kg})\end{array}$ & 98,2 & 97,7 & & 98.3 & 97.6 & \\
$\begin{array}{l}\text { Fileen } \\
\text { poikkipinta- } \\
\text { ala }\left(\mathrm{cm}^{2}\right)\end{array}$ & 40,4 & 43,1 & $* *$ & 42.7 & 40.8 & \\
$\begin{array}{l}\text { Lihassolun } \\
\text { poikkipinta- } \\
\text { ala } \mathrm{x} 10^{3}\end{array}$ & 3,9 & 4,5 & $* *$ & 4.2 & 4.1 \\
$\left(\mu \mathrm{m}^{2}\right)$ & & & & & \\
\hline$* * \mathrm{P}<0,01$ & & & & &
\end{tabular}




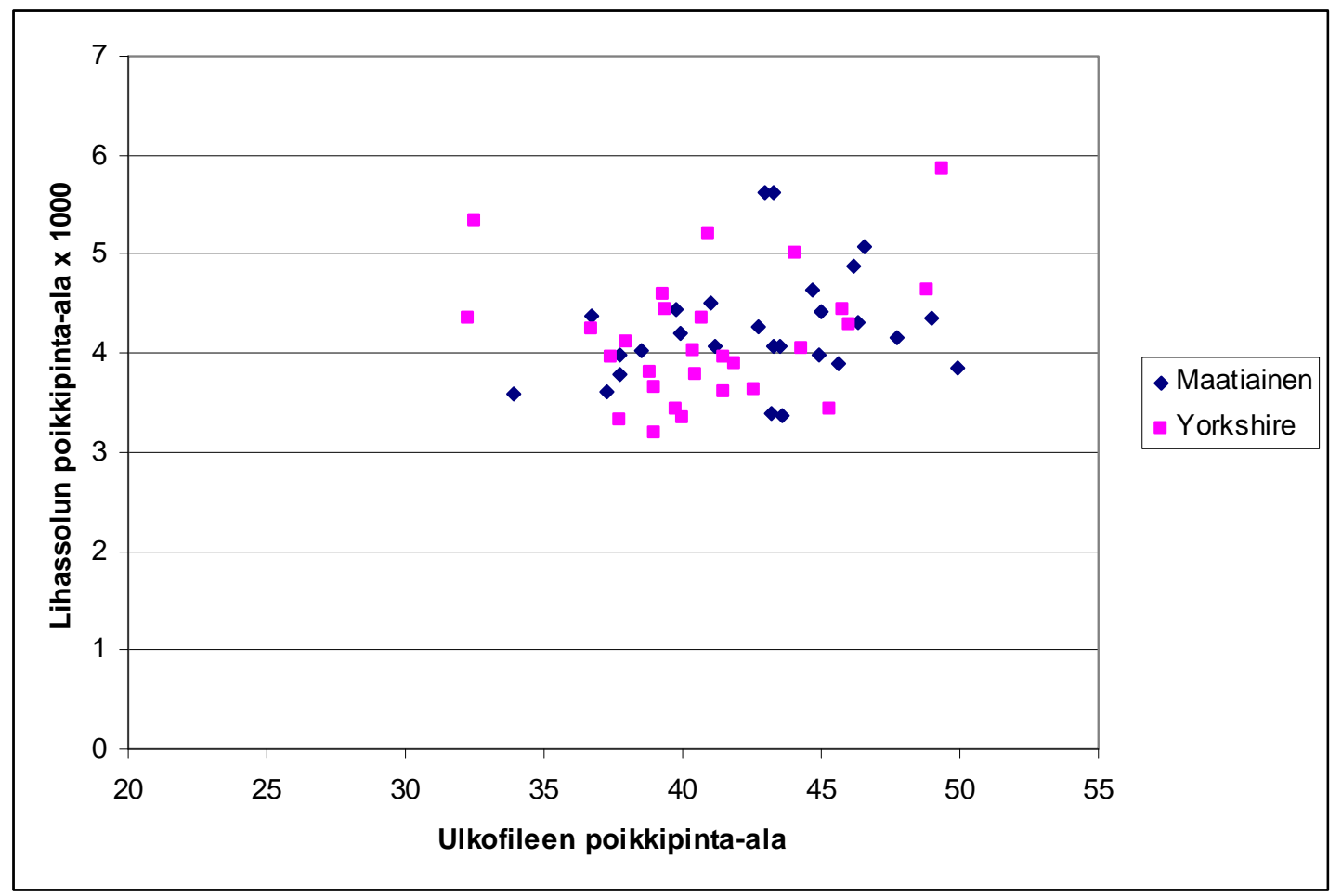

Kuva 1. Keskimääräinen lihassolun poikkipinta-ala $\left(\mu \mathrm{m}^{2}\right)$ longissimus dorsi-lihaksessa suhteessa fileen poikkipinta-alaan $\left(\mathrm{cm}^{2}\right)$ maatiaisessa ja yorkshiressa.

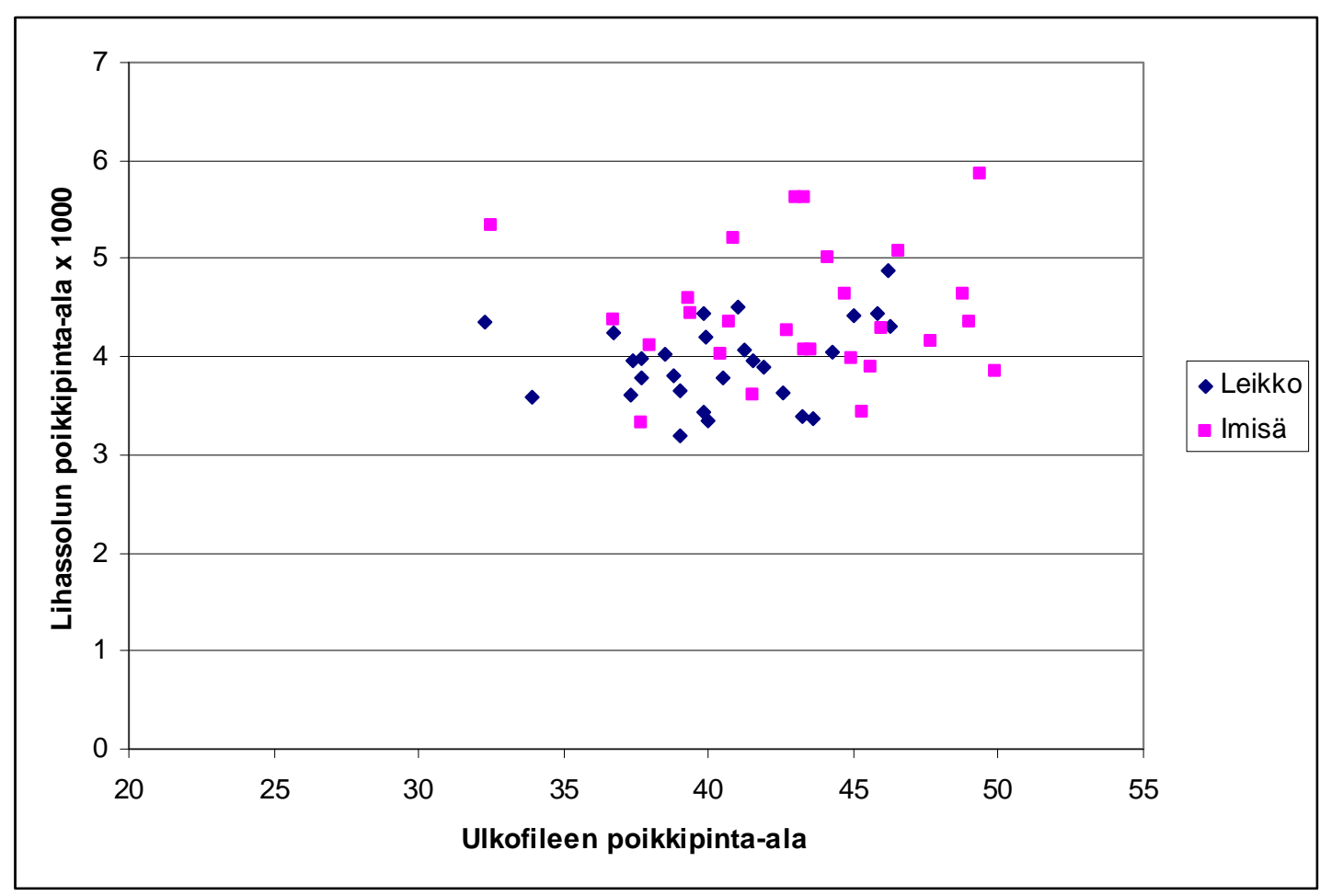

Kuva 2. Keskimääräinen lihassolun poikkipinta-ala $\left(\mu \mathrm{m}^{2}\right)$ longissimus dorsi -lihaksessa suhteessa fileen poikkipinta-alaan $\left(\mathrm{cm}^{2}\right)$ leikoissa ja imisissä. 